\title{
Dairy cows increase ingestive mastication and reduce ruminative chewing when grazing chicory and plantain
}

\author{
P. Gregorini, ${ }^{1}$ E. M. K. Minnee, W. Griffiths, and J. M. Lee \\ DairyNZ Ltd., Private Bag 3221, Hamilton 3240, New Zealand
}

\begin{abstract}
Although the nutritive value of chicory (Cichorium intybus L.) and plantain (Plantago lanceolata L.) has been thoroughly studied, little is known about the grazing behavior of cattle feeding on chicory and plantain swards. The objective of the present study was to assess and describe the grazing behavior of dairy cows as affected by dietary proportions of chicory and plantain fed as monocultures for part of the day. Ninety Holstein-Friesian cows (489 $\pm 42 \mathrm{~kg}$ of body weight; $4.1 \pm$ 0.3 body condition score, and $216 \pm 15 \mathrm{~d}$ in milk) were randomly assigned to 15 groups (6 cows per group) and grazed according to 7 treatments: control (CTL, 3 groups), perennial ryegrass (Lolium perenne L.) dominant sward (24-h pasture strip); 3 chicory treatments comprising 20,40 , and $60 \%$ of the diet, strip-grazing a monoculture of chicory to a fixed postgrazing residual before strip-grazing a perennial ryegrass dominant sward (2 groups of cows per treatment); and 3 plantain treatments comprising 20, 40, and $60 \%$ of the diet, strip-grazing a monoculture of plantain to a fixed postgrazing residual before strip-grazing a perennial ryegrass dominant sward (2 groups of cows per treatment). Four focal animals per group were equipped with 3 -dimensional motion sensors, which provided the number of steps taken at each minute of the day. These cows were also fitted with automatic jaw-movement recorders that identified bites, mastication during ingestion, chewing during rumination, and determined grazing, rumination and idling times and bouts. Daily grazing time and bouts were not affected by treatments but rumination time differed and was reduced by up to 90 min when cows were allocated to chicory and plantain as $60 \%$ of their diet. Ruminative chewing was reduced in cows grazing chicory and plantain by up to $20 \%$ in cows allocated to the $60 \%$ treatments. Compared with perennial ryegrass, as the dietary proportion of chicory and plantain increased, cows spent more time idling and less time ruminating, and increased ingestive
\end{abstract}

Received April 23, 2013

Accepted August 24, 2013.

${ }^{1}$ Corresponding author: Pablo.Gregorini@dairynz.co.nz mastications 5 and 3 times for chicory and plantain, respectively. Cows allocated to chicory and plantain reduced bite rate and bites per grazing step linearly, and increased the number of mastications per bite of pasture dry matter intake while grazing pasture after having grazed chicory and plantain. These results indicate that cows grazing chicory and plantain masticate more during ingestion and reduce rumination time and chewing. They also suggest that chicory presents greater constraints to ingestion than does plantain. Thus, although chicory has been considered to have a greater nutritive value than plantain, its overall feeding value may be no greater than that of plantain.

Key words: dairy cow, grazing behavior, chicory, plantain

\section{INTRODUCTION}

Maintaining reasonable quality and acceptable production of pasture all year round is becoming more difficult in dairy farms with increasing incidence of high stocking rate, nonpersistent grass cultivars, and dry summers. Under these circumstances, the use of alternative forage species such as chicory (Cichorium intybus L.) and plantain (Plantago lanceolata L.) has been considered to maintain or increase forage production (Belesky et al., 1999; Sanderson et al., 2003a; Labreveux et al., 2006). Compared with perennial ryegrass (Lolium perenne L.), vegetative chicory and plantain generally have lower fiber and $\mathrm{N}$ and greater mineral contents. Chicory has greater OM digestibility and energy ( $\mathrm{ME} / \mathrm{kg}$ of $\mathrm{OM}$ ) than perennial ryegrass, whereas true $\mathrm{OM}$ digestibility of plantain is as high as that of perennial ryegrass (Dryden et al., 1995; Stewart, 1996; Barry, 1998). Although the nutritive value of chicory and plantain has been thoroughly studied and reviewed, only limited data are available on the grazing behavior of cattle feeding on chicory and plantain swards, which ultimately determines their feeding value.

Rumen function in cattle is linked to the ingestive actions of the grazing process, which are mainly determined by sward structure (Laca and Demment, 1991; Demment and Laca, 1994; Gregorini, 2012); 
these include ingestive mastication, particle breakdown kinetics and size swallowed, and fermentation in the rumen. Derrick et al. (1993) reported that the chewing rate of cows fed fresh plantain was greater than that for perennial ryegrass, which may lead to the ingestion of smaller particles of forage. Dryden et al. (1995) and Kusmartono et al. (1996) measured faster particle breakdown kinetics for chicory, which allowed for faster digesta outflow from the rumen. These 3 studies, however, were conducted using either deer or sheep grazing artificial swards for only $1.5 \mathrm{~min}$. Although Clark et al. (1990) and McCoy et al. (1997) reported grazing behavior data of cattle feeding on chicory, these studies were conducted with bulls grazing reproductive chicory in a leader-follower system and tethered beef cows grazing for only $1 \mathrm{~h}$, respectively. Thus, studies comparing the grazing behavior of dairy cows feeding on vegetative chicory and plantain monocultures compared with perennial ryegrass dominant swards are lacking. Such studies will provide better understanding of cattle's ingestive and potentially digestive responses to chicory and plantain swards, and assist in the design of specific grazing management procedures when including herbs in the diet of dairy cows.

The objective of the present study was to assess and describe the grazing behavior dynamics of dairy cows as affected by proportions of chicory and plantain in the diet fed as monocultures under field conditions. At the same time, this study also tested the hypothesis that dairy cows grazing chicory or plantain increase ingestive mastication and reduce bite rate compared with those grazing perennial ryegrass swards.

\section{MATERIALS AND METHODS}

This study was approved by the Committee of Animal Care and Use from AgResearch, \#12548 (Hamilton, New Zealand).

\section{Research Site, Treatments, and Experimental Procedures}

The study was conducted at Scott Farm, DairyNZ, Hamilton, New Zealand $\left(37^{\circ} 47^{\prime} \mathrm{S}, 175^{\circ} 19^{\prime} \mathrm{E}, 40 \mathrm{~m}\right.$ above sea level) during February and March 2013.

Ninety Holstein-Friesian cows [489 $\pm 42 \mathrm{~kg}$ of BW; $4.1 \pm 0.3$ BCS (scale 1-10), $216 \pm 15$ DIM, $13.2 \pm 1.1$ $\mathrm{kg} / \mathrm{d}$ of milk production] were allocated to 15 herds each with 6 cows, balanced for milk yield, age, and BW. These 15 herds were randomly allocated to the following treatments: control (CTL), strip-grazing a perennial ryegrass (Lolium perenne L.) dominant sward (24-h pasture break allocated at $0800 \mathrm{~h}$ ); chicory as 20,40 , and $60 \%$ of the diet, strip-grazing a monocul- ture of a second-year chicory crop (fixed postgrazing residual and crop strip allocated at $0800 \mathrm{~h}$ ) and then strip-grazing a perennial ryegrass dominant sward; and plantain as 20,40 , and $60 \%$ of the diet, strip-grazing a monoculture of a second-year plantain crop (fixed postgrazing residual and crop strip allocated at $0800 \mathrm{~h}$ ) and then strip-grazing a perennial ryegrass dominant sward. Three groups of cows were allocated to CTL, whereas 2 groups of cows were allocated to each of the 6 chicory and plantain treatments.

Cows in all treatments grazed the same perennial ryegrass dominant sward for a 2 -d preadaptation period and were then adapted to the treatments for a period of $4 \mathrm{~d}$, during which the daily allocations of chicory and plantain were gradually increased to the desired proportion. Measurements took place during the next 4 $\mathrm{d}$ of the following week.

The daily target of forage intake (chicory or plantain plus pasture or pasture alone) was $15 \mathrm{~kg}$ of $\mathrm{DM} /$ cow per day for all treatments. Mean $( \pm \mathrm{SD})$ pregrazing herbage mass of CTL swards and chicory and plantain monocultures were 2,930 $\pm 336,2,710 \pm 364$, and $2,620 \pm 240 \mathrm{~kg}$ of $\mathrm{DM} / \mathrm{ha}$, respectively. The pregrazing herbage mass of the perennial ryegrass sward grazed after chicory and plantain was $3,160 \pm 179 \mathrm{~kg}$ of DM/ ha. We aimed for residuals of chicory and plantain and perennial ryegrass swards of between 700 and 800 and $1,500 \mathrm{~kg}$ of $\mathrm{DM} / \mathrm{ha}$, respectively. Areas of chicory and plantain pastures were adjusted accordingly to meet the desired proportion of chicory and plantain in the diet.

Cows were milked at $0700 \mathrm{~h}$ and $1500 \mathrm{~h}$. Cows were not fed supplements and had ad libitum access to fresh water during grazing.

\section{Measurements and Calculations}

All the measurements were taken during the 1-wk measurement period and the specific calculations presented below refer to that period. Four random cows per group (focal animals) were equipped with IceTags 3D motion sensors (Ice Robotics Ltd., Edinburgh, UK) for the duration of the study. This device provided the number of steps taken by the cow at each minute of the day. IceTags 3D motion sensors have been previously used in a similar grazing context as that in the present study (Gregorini et al., 2011). The sensors were attached during milking on the left hind leg. On 4 occasions (dates), 1 focal cow from each treatment and 2 from CTL were monitored for grazing behavior. Different cows were measured on each of the 4 dates. These dates are referred to as measurement groups in the statistical analysis. Measurement group was included as a blocking factor to remove differences due to 
day; for example, pasture and weather differences. The focal cows were randomly fitted with automatic jawmovement recorders from the Institute of Grassland and Environmental Research, North Wyke, UK (Rutter et al., 1997) over $24 \mathrm{~h}$. The recorder was fitted immediately after morning milking period $(\sim 0800 \mathrm{~h})$. All cows were previously adapted to the equipment before the adaptation period. Data obtained from the automatic jaw-movement recordings were analyzed using Graze software (Rutter, 2000) to identify and characterize jaw movements [prehension (bites), mastication during ingestion, and chewing during rumination], to determine bouts of grazing, ruminating, and idling activities, as well as daily grazing, rumination, and idling times.

Pre- and postgrazing herbage masses from the perennial ryegrass pasture breaks were measured using the rising plate meter and a calibration equation $(\mathrm{kg}$ of herbage $\mathrm{DM} /$ ha $=182.38 \times$ reading of the rising plate meter +264.82$)$ created during the trial (190 herbage cuts to ground level of $0.1 \mathrm{~m}^{2}$ ), whereas chicory and plantain were estimated with pre- and postgrazing herbage cuts to ground level. Daily DMI of perennial ryegrass, chicory, and plantain was estimated by the difference between pre- and postgrazing herbage mass (Stockdale and King, 1983; Macoon et al., 2003).

Data from the jaw-movement recordings were used to calculate specific jaw movement per bite, herbage DMI, and grazing steps while cows were grazing chicory, plantain, and pasture. Grazing steps were calculated merging step data from the IceTags and the jaw-movement recordings by counting steps only when cows were grazing.

Herbage from chicory and plantain swards was sampled ( $\sim 200 \mathrm{~g}$ of fresh weight per sample) for herbage quality. Samples were oven-dried at $60^{\circ} \mathrm{C}$ to constant weight $(\sim 48 \mathrm{~h})$, ground to pass through a 1-mm sieve (Christy Lab Mill, Suffolk, UK), and analyzed for nutritive characteristics using wet chemistry techniques by Hill Laboratories (Hamilton, New Zealand). In vitro OM digestibility was determined using the pepsincellulase method (AFIA, 2006).

\section{Statistical Analysis}

Each variable was analyzed by ANOVA, including measurement group (group of cows) as a blocking factor and treatment as a fixed effect. Linear and quadratic contrasts of chicory and plantain proportion of the diet were tested in the analysis. GenStat 14.1 was used for the statistical analyses (Genstat, 2011).

\section{RESULTS}

Table 1 shows the nutritive characteristic of the forages grazed in this study. Table 2 shows the daily time- lines for behavioral activities (i.e., including time spent on both pasture and herbs). Daily grazing time $(P=$ $0.70)$, number of grazing bouts $(P=0.81)$, and time per grazing bouts $(P=0.73)$ were not different between CTL cows and cows fed different proportions of chicory and plantain. Bite mass was smaller $(P=0.02)$ for CTL cows $(0.41 \mathrm{~g}$ of DM) than for cows grazing chicory $(0.55$ $\pm 0.05 \mathrm{~g}$ of $\mathrm{DM})$ or plantain $(0.59 \pm 0.10 \mathrm{~g}$ of DM), respectively. Rumination time also differed and was reduced by up to 90 min when cows were allocated to chicory and plantain as $60 \%$ of their diet $(P<0.001)$. The daily number of ruminative chews was also reduced when cows grazed chicory or plantain by up to $20 \%$ for cows allocated to the $60 \%$ treatments $(P<0.001)$. The number of rumination bouts per day was not affected by treatment $(18 \pm 1.7 ; P=0.58)$. As the proportion of herbs in the diet increased, cows spent more time idling $(P<0.001)$. Compared with the CTL cows, cows fed the highest allocation of chicory and plantain increased idling time by approximately $120 \mathrm{~min}$.

Treatments did not affect the total number of steps $(3,540 \pm 354 ; P=0.46)$ or grazing steps per day $(1,757$ $\pm 237 ; P=0.55)$. Control cows had fewer mastications per grazing step compared with cows grazing chicory or plantain $(2.4,9.1 \pm 3.6$, and $7.5 \pm 2.3$ for CTL, chicory, and plantain, respectively; $P<0.001$; Table 2). Cows grazing chicory or plantain reduced bite rates (bites per min of grazing) and took fewer bites per min of grazing as the proportion of chicory or plantain increased, resulting in a reduction of up to 20 bites in the $60 \%$ treatment $(P<0.001)$. The ratio of mastications:bite (number of ingestive mastications per severed bite) increased linearly by 8 and 6 times, and the number of mastications per kilogram of DM eaten also increased linearly by 4 and 2.5 times, with the proportion of chicory and plantain in the diet $(P<0.001)$. As the proportion of chicory and plantain allocated increased, the number of bites severed per grazing step tended to decrease $(23,13$, and $16, P=0.06$, and 18,17 , and 14 ,

Table 1. Chemical composition and nutritive characteristic of herbage from chicory and plantain monocultures and perennial ryegrass dominated swards (\% of DM unless otherwise noted)

\begin{tabular}{lccc}
\hline Item $^{1}$ & $\begin{array}{c}\text { Perennial } \\
\text { ryegrass }\end{array}$ & Chicory & Plantain \\
\hline CP & 18.8 & 20.6 & 20.4 \\
NDF & 45.5 & 22.2 & 28.1 \\
ADF & 29.6 & 24.2 & 26.2 \\
WSC & 7.5 & 14.5 & 12.7 \\
Starch & 0.9 & 1.5 & 1.8 \\
Ash & 8.4 & 11.2 & 11.3 \\
OMD & 65.7 & 77.9 & 72.1 \\
ME, MJ $/ \mathrm{kg}$ of DM & 10.5 & 12.5 & 11.5 \\
\hline
\end{tabular}

${ }^{1} \mathrm{WSC}=$ water soluble carbohydrates; OMD $=$ in vitro OM digestibility. 
$P=0.07$, for 20,40 , and $60 \%$ chicory and plantain in the diet, respectively).

Total forage DMI was not affected by treatment (16 $\pm 0.7 \mathrm{~kg}$ of DM; $P=0.30)$. Estimated pasture DMI, however, was less when both chicory and plantain were included in the diet compared with the CTL treatment $(P<0.001)$ and decreased linearly $(P<0.001)$ as the proportion of chicory or plantain in the diet increased (14.6, 11.3, and 6.7, and 13.4, 10.1, and $7.2 \mathrm{~kg}$ of DM for 20,40 , and $60 \%$ chicory and plantain in the diet, respectively). The herb DMI increased linearly with and increasing proportion of chicory or plantain in the $\operatorname{diet}(P<0.001)$. The DMI of chicory was, on average, $5 \%$ less than that of plantain $(P<0.001)$.

The grazing behavior of cows grazing on chicory or plantain monocultures is presented in Table 3. Cows grazing chicory made, on average, $20 \%$ more mastications per minute of grazing than plantain. In both cases, increasing the proportion of chicory or plantain in the diet increased the number of ingestive mastications $(P$ $<0.001)$. The bite rate tended to be $7.5 \%$ greater for cows grazing plantain than for those grazing chicory $(P$ $=0.07$ ), when the percentage of dietary herbs was $20 \%$. The number of bites per grazing step did not differ between chicory and plantain $(P=0.40)$, whereas, on average, the number of mastications per bite was $26 \%$ greater for cows grazing chicory than for cows grazing plantain $(P<0.01)$.

Table 4 presents the grazing behavior of cows grazing ryegrass after grazing chicory or plantain. Cows moving from chicory to ryegrass had an average bite rate greater than that of cows moving from plantain (51 vs. 48 bites per min respectively; $P<0.001$ ). The average number of mastications per minute of grazing was also greater for cows moving from chicory to ryegrass compared with cows moving from plantain to ryegrass (23 vs. 17 mastications per min of grazing; $P<0.001)$. Mastications per bite increased as cows moved from greater chicory and plantain allocation to ryegrass $(P<0.001)$, and the magnitude of this increment was about $14 \%$ greater for chicory than for the plantain treatments $(P<0.001)$. The number of mastications per kilogram of pasture DM eaten followed the same pattern $(P=0.02)$. The greater the proportion of chicory and plantain allocated to the cows, the greater the number of mastications observed. On average, cows moving from chicory to ryegrass made 330 mastications more per kilogram of pasture DM eaten compared with cows moving from plantain to ryegrass. Cows moving from higher proportions of chicory and plantain also took fewer bites at each grazing step, by up to $42 \%$ less when comparing $60 \%$ treatments with $20 \%$ treatments.

\section{DISCUSSION}

Ingestive mastication was greater with cows grazing chicory and plantain compared with those grazing ryegrass. Ingestive mastication has been related to differences in morphological characteristics of the sward (Burns and Sollenberger, 2002; Drescher et al., 2006; Gregorini et al., 2009a). The sward canopies of chicory and plantain have greater leaf mass and accessibility of leaves, which allow cows to take big bites (Stewart, 1996; McCoy et al., 1997). However, big bites require more mouth-handling and mastication before swallowing, which slows bite rate and reduces intake rate (Laca and Demment, 1991; Laca et al., 1992). In this study, bite mass (g of DM) was greater for chicory and plantain than for CTL $(0.83,0.76$, and $0.6 \mathrm{~g}$ of DM, respectively). However, the number of mastications per bite and kilograms of DM eaten were markedly greater for cows grazing chicory and plantain than for those grazing ryegrass. Thus, fresh broad leaves of chicory and plantain require more mastication (also known as handling) to accommodate leaves in the oral cavity to form a bolus. This premise is supported by the results of Derrick et al. (1993), who reported greater mastication and manipulative activity for sheep grazing broadleaved forages than those grazing ryegrass. The leaves of chicory and plantain have very low fiber content compared with ryegrass (Hoskin et al., 1995). In the current study, the fiber (NDF) content of chicory and plantain was 2 and 1.6 times less than that of ryegrass, respectively (Table 1). The fiber content of leaves has been shown to be positively related to toughness and negatively related to the rate of reduction of forage particle size (Wright and Illius, 1995; Gregorini et al., 2009c). Therefore, the structural and morphological characteristics of the canopies of chicory and plantain swards make grazing cattle masticate more during ingestion of herbage, and the lower content of fiber increases the mastication efficiency. This suggests that cows grazing chicory and plantain swallow smaller herbage particles than those grazing ryegrass; thus, faster rumen turnover and greater fermentation rates, as well as changes in rumination patterns, can be expected.

Cows grazing chicory or plantain reduced rumination time and ruminative chews compared with those grazing ryegrass. We also observed that cows grazing chicory or plantain reduced ruminative chews per rumination bolus by approximately $9 \%$ and its rate (chew/ min of rumination time per bolus) by $6 \%$ compared with those grazing ryegrass. Rumination is considered to be a key component of rumen digestion and has the primary function of facilitating clearance of digesta from the rumen by reduction of particle size (Murphy 


\begin{tabular}{|c|c|c|c|c|c|c|c|c|}
\hline & & & & & & & & \\
\hline \multicolumn{3}{|c|}{ Plantain $^{2}$} & \multirow[b]{2}{*}{ SED } & \multirow[b]{2}{*}{ Treatment } & \multicolumn{2}{|c|}{ Chicory } & \multicolumn{2}{|c|}{ Plantain } \\
\hline $20 \%$ & $40 \%$ & $60 \%$ & & & $\mathrm{~L}$ & $\mathrm{Q}$ & $\mathrm{L}$ & $\mathrm{Q}$ \\
\hline 590 & 567 & 541 & 25.6 & 0.70 & 0.75 & 0.49 & 0.28 & 0.19 \\
\hline 415 & 438 & 386 & 17.5 & $<0.01$ & $<0.01$ & 0.23 & $<0.01$ & 0.76 \\
\hline 25,764 & 25,114 & 22,182 & 1,075 & $<0.01$ & $<0.01$ & 0.03 & $<0.01$ & 0.63 \\
\hline 415 & 401 & 481 & 31.7 & $<0.01$ & $<0.01$ & 0.26 & $<0.01$ & 0.86 \\
\hline 3,271 & 3,95 & 3,205 & 414 & 0.46 & 0.63 & 0.18 & 0.36 & 0.83 \\
\hline 31,709 & 26,918 & 22,109 & 2,559 & $<0.01$ & $<0.01$ & 0.8 & $<0.01$ & 0.78 \\
\hline 53.8 & 47.5 & 40.8 & 3.65 & $<0.01$ & $<0.01$ & 0.75 & $<0.01$ & 0.67 \\
\hline 0.8 & 0.7 & 0.6 & 0.03 & $<0.01$ & $<0.01$ & 0.41 & $<0.01$ & 0.26 \\
\hline 8,605 & 13,598 & 13,642 & 218 & $<0.01$ & $<0.01$ & 0.78 & $<0.01$ & 0.20 \\
\hline 14.5 & 23.9 & 25.4 & 3.48 & $<0.01$ & $<0.01$ & 0.83 & $<0.01$ & 0.31 \\
\hline 0.3 & 0.5 & 0.6 & 0.09 & $<0.01$ & $<0.01$ & 0.47 & $<0.01$ & 0.80 \\
\hline 550 & 941 & 865 & 228 & $<0.01$ & $<0.01$ & 0.38 & $<0.01$ & 0.16 \\
\hline 16.3 & 15.3 & 16.1 & 1.69 & 0.39 & 0.38 & 0.57 & 0.27 & 0.49 \\
\hline
\end{tabular}

Grazing time, $\mathrm{min} / \mathrm{d}$

Ruminative chews, chews/d

z Idling time, $\mathrm{min} / \mathrm{d}$

Daily steps, steps/d

$\vec{N}$ Bite rate, bites/grazing min

N Bites:total jaw movements

$\vec{\omega}$ Mastications

\begin{tabular}{|c|c|c|c|c|c|c|c|c|c|c|c|c|c|}
\hline No./d & 4,209 & 11,457 & 13,975 & 20,301 & 8,605 & 13,598 & 13,642 & 218 & $<0.01$ & $<0.01$ & 0.78 & $<0.01$ & 0.20 \\
\hline No./min of grazing & 7.6 & 19.5 & 24.2 & 35.0 & 14.5 & 23.9 & 25.4 & 3.48 & $<0.01$ & $<0.01$ & 0.83 & $<0.01$ & 0.31 \\
\hline No./bite & 0.1 & 0.3 & 0.5 & 0.8 & 0.3 & 0.5 & 0.6 & 0.09 & $<0.01$ & $<0.01$ & 0.47 & $<0.01$ & 0.80 \\
\hline Jo. $/ \mathrm{kg}$ of DM eaten & 287 & 771 & 884 & 1,602 & 550 & 941 & 865 & 228 & $<0.01$ & $<0.01$ & 0.38 & $<0.01$ & 0.16 \\
\hline otal forage intake, $\mathrm{kg}$ of $\mathrm{DM} / \mathrm{d}$ & 14.0 & 16.8 & 16.9 & 15.3 & 16.3 & 15.3 & 16.1 & 1.69 & 0.39 & 0.38 & 0.57 & 0.27 & 0.49 \\
\hline
\end{tabular}

${ }^{1}$ Control = Lolium perenne $\mathrm{L}$. based sward.

${ }^{2}$ Dietary percentage of chicory and plantain allocated as monocultures.

${ }^{3} \mathrm{~L}=$ linear effect; $\mathrm{Q}=$ quadratic effect.

Table 3. Effects of dietary percentage of chicory and plantain allocated as monocultures on grazing behavior and herb intake of dairy cows grazing chicory and plantain swards

\begin{tabular}{|c|c|c|c|c|c|c|c|c|c|c|c|c|}
\hline \multirow[b]{3}{*}{ Variable } & \multirow{2}{*}{\multicolumn{3}{|c|}{ Chicory $^{1}$}} & \multirow{2}{*}{\multicolumn{3}{|c|}{ Plantain $^{1}$}} & \multirow[b]{3}{*}{ SED } & \multicolumn{5}{|c|}{$P$-value ${ }^{2}$} \\
\hline & & & & & & & & \multirow[b]{2}{*}{ Treatment } & \multicolumn{2}{|c|}{ Chicory } & \multicolumn{2}{|c|}{ Plantain } \\
\hline & $20 \%$ & $40 \%$ & $60 \%$ & $20 \%$ & $40 \%$ & $60 \%$ & & & $\mathrm{~L}$ & $\mathrm{Q}$ & $\mathrm{L}$ & $\mathrm{Q}$ \\
\hline Grazing time, min & 94 & 153 & 240 & 151 & 188 & 252 & 23.1 & $<0.01$ & $<0.01$ & 0.49 & $<0.01$ & 0.51 \\
\hline Grazing steps, steps & 277 & 624 & 730 & 355 & 551 & 760 & 169 & 0.06 & 0.02 & 0.42 & 0.03 & 0.96 \\
\hline Grazing step rate, steps/min & 2.9 & 3.9 & 3.0 & 2.7 & 3.0 & 3.0 & 0.82 & 0.72 & 0.88 & 0.19 & 0.67 & 0.84 \\
\hline Grazing bouts, bouts & 1.8 & 2.6 & 1.0 & 1.00 & 1.2 & 2.2 & 0.67 & 0.27 & 0.31 & 0.16 & 0.10 & 0.48 \\
\hline Bite rate, bites/grazing min & 41.4 & 36.2 & 41.7 & 51.4 & 37.9 & 38.9 & 4.70 & 0.07 & 0.93 & 0.21 & 0.02 & 0.09 \\
\hline Bites:total jaw movements & 0.6 & 0.5 & 0.5 & 0.7 & 0.5 & 0.5 & 0.04 & $<0.01$ & 0.05 & 0.21 & $<0.01$ & $<0.01$ \\
\hline Bite mass, $g$ of DM & 0.6 & 1.1 & 0.9 & 0.5 & 0.9 & 0.9 & 0.22 & 0.10 & 0.24 & 0.05 & 0.05 & 0.28 \\
\hline Bites:grazing step & 14.5 & 10.6 & 14.2 & 22.0 & 13.2 & 15.9 & 5.2 & 0.40 & 0.95 & 0.41 & 0.25 & 0.23 \\
\hline \multicolumn{13}{|l|}{ Mastications } \\
\hline No./bite & 0.7 & 1.0 & 1.0 & 0.3 & 0.9 & 0.8 & 0.16 & $<0.01$ & 0.07 & 0.31 & $<0.01$ & 0.01 \\
\hline No./grazing step & 32.7 & 17.9 & 15.8 & 19.2 & 13.9 & 10.5 & 7.81 & 0.15 & 0.04 & 0.36 & 0.28 & 0.88 \\
\hline Herb DMI, $\mathrm{kg}$ of DM/ d & 2.4 & 5.0 & 7.0 & 2.8 & 5.4 & 8.9 & 0.53 & $<0.01$ & $<0.01$ & 0.53 & $<0.01$ & $<0.01$ \\
\hline
\end{tabular}

${ }^{1}$ Dietary percentage of chicory and plantain allocated as monocultures.

${ }^{2} \mathrm{~L}=$ linear effect; $\mathrm{Q}=$ quadratic effect. 
et al., 1983; Kennedy et al., 2005). Kennedy (1985) observed that the number of ruminative chews per bolus diminished with bolus fragility, suggesting that ruminative chewing per bolus reflected the extent of large particle breakdown in the rumen. Furthermore, unpublished results (P. Gregorini; unpublished data) suggest that a reduction in ruminative chews per bolus is evidence for a reduced need for rumination, due to greater particle breakdown during ingestion. Particle breakdown also facilitates microbial colonization and, thereby, digestion of forage particles. This further demonstrates that particles swallowed by cows grazing chicory and plantain were likely smaller and that rumen fermentation rates greater compared with those grazing ryegrass.

The results suggest that clearance of digesta from the rumen will be faster for cows grazing chicory and plantain than for those grazing ryegrass. It has been shown that clearance of digesta from the rumen clears room and stimulates feeding, and thereby grazing time (Kennedy et al., 2005; Gregorini et al., 2007, 2009b). Daily grazing time did not differ between treatments, although idling time increased with the proportion of chicory and plantain in the diet and followed the decrease in rumination time (Table 2). The need to ruminate has been considered as a constraint to grazing (Penning et al., 1991; Gibb et al., 1997; Gibb, 2007). Then, if the rumination constraint was reduced, why did cows grazing chicory and plantain not graze longer? Why did cows grazing chicory graze for shorter periods and consume less herb ( $\mathrm{kg}$ of $\mathrm{DM}$ ) if chicory has a greater nutritive value than plantain? In the current study, in vitro OM digestibility of chicory and plantain were 780 and $720 \mathrm{~g} / \mathrm{kg}$ of DM (Table 1). A plausible explanation could be a greater rumen fermentation rate, because it is one of the key factors controlling satiety and cessation of a meal (Illius and Jessop, 1996). Therefore, we propose that the cows grazing chicory reached greater levels of satiation faster than those grazing plantain and ryegrass. This inference is supported by the grazing behavior on pasture after cows had grazed chicory and plantain. Cows allocated increasing proportions of chicory and plantain increased the number of mastications per bite linearly and reduced the number of bites severed per grazing step, as well as increased the number of mastications per pasture DMI (being greater for chicory than plantain) after cows grazed the herbs (Table 4). Previous studies have shown that dairy and beef cattle reduce the number of bites severed per grazing step and increase mastication per bite as satiety increases (Gregorini et al., 2007, 2011; Gregorini, 2011).

In the current study, cows consumed less chicory (approximately $20 \%$; Table 3 ) compared with plantain, de- 
spite similar herb mass allocation and greater in vitro OM digestibility (Table 1). This may reflect harvesting constraints [i.e., increased difficulty in severing a bites (e.g., as a result of reproductive stems in a second year chicory crop) and forming a proper bolus to masticate and swallow], further reflecting the trend of lower bite rate and greater number of mastications per bite. Therefore, although chicory has been considered to have a greater nutritive value than plantain (Sanderson et al., 2003b; Labreveux et al., 2006), its nutritive value may be compromised by the constraints of harvesting and ingestion; thus, its overall feeding value may be no greater than that of plantain.

\section{ACKNOWLEDGMENTS}

This work was funded by New Zealand dairy farmers. The authors thank DairyNZ Inc. (Hamilton, New Zealand) and Sharon Woodward and Viliami Taufa (Dairy NZ) for reviewing this work and manuscript, and Garry Waghorn (Dairy NZ) for his useful comments during the writing of the manuscript. The statistical analysis was conducted by Barbara Dow (Dairy NZ); her help and inputs are very much appreciated.

\section{REFERENCES}

AFIA (Australian Fodder Industry Association). 2006. Determination of digestibility using the pepsin-cellulase method. Method 1.7R. AFIA Laboratory Methods Manual. Australian Fodder Industry Association Ltd., Melbourne, Australia.

Barry, T. 1998. The feeding value of chicory (Cichorium intybus) for ruminant livestock. J. Agric. Sci. (Camb.) 131:251-257.

Belesky, D. P., J. M. Fedders, K. E. Turner, and J. M. Ruckle. 1999 Productivity, botanical composition, and nutritive value of swards including forage chicory. Agron. J. 91:450-456.

Burns, J., and L. Sollenberger. 2002. Grazing behavior of ruminants and daily performance from warm-season grasses. Crop Sci. 42:873-881.

Clark, D., C. Anderson, and G. Hongwen. 1990. Liveweight gain and intake of Friesian bulls grazing 'Grasslands Puna' chicory (Cichorium intybus L.) or pasture. N. Z. J. Agric. Res. 33:219-224.

Demment, M., and E. Laca. 1994. Reductionism and synthesis in the grazing sciences: Models and experiments. Proc. Aust. Soc. Anim. Prod. 20:6-16.

Derrick, R., G. Moseley, and D. Wilman. 1993. Intake, by sheep, and digestibility of chickweed, dandelion, dock, ribwort and spurrey, compared with perennial ryegrass. J. Agric. Sci. (Camb.) 120:5161.

Drescher, M., I. Heitkönig, J. G. Raats, and H. H. Prins. 2006. The role of grass stems as structural foraging deterrents and their effects on the foraging behaviour of cattle. Appl. Anim. Behav. Sci. 101:10-26.

Dryden, G. M., K. Stafford, G. Waghorn, and T. Barry. 1995. Comminution of roughages by red deer (Cervus elaphus) during the prehension of feed. J. Agric. Sci. 125:407-414.

GenStat. 2011. GenStat for Windows. 14th ed. VSN International, Hemel Hempstead, UK.

Gibb, M. 2007. Grassland management with emphasis on grazing behaviour. Pages 141-157 in Fresh Herbage for Dairy Cattle. A. Elgersma, Dijkstra, J, Tamminga, S, ed. Springer, Wageningen, the Netherlands.
Gibb, M., C. Huckle, R. Nuthall, and A. Rook. 1997. Effect of sward surface height on intake and grazing behaviour by lactating Holstein Friesian cows. Grass Forage Sci. 52:309-321.

Gregorini, P. 2011. Internal state. Stimuli motivating herbage intake and certain ingestive behaviours in grazing ruminants. Pages 291320 in Producción Animal en Pastoreo. C. A. Cangiano and M. A. Brizuela, ed. Buenos Aires, Argentina. Ediciones INTA, Buenos Aires, Argentina.

Gregorini, P. 2012. Diurnal grazing pattern: Its physiological basis and strategic management. Anim. Prod. Sci. 52:416-430.

Gregorini, P., C. Clark, K. McLeod, C. Glassey, A. Romera, and J. Jago. 2011. Short communication: Feeding station behavior of grazing dairy cows in response to restriction of time at pasture. Livest. Sci. 137:287-291.

Gregorini, P., S. Gunter, P. Beck, J. Caldwell, M. Bowman, and W. Coblentz. 2009a. Short-term foraging dynamics of cattle grazing swards with different canopy structures. J. Anim. Sci. 87:38173824 .

Gregorini, P., S. Gunter, C. Masino, and P. Beck. 2007. Effects of ruminal fill on short-term herbage intake rate and grazing dynamics of beef heifers. Grass Forage Sci. 62:346-354.

Gregorini, P., K. Soder, and R. Kensinger. 2009b. Effects of rumen fill on short-term ingestive behavior and circulating concentrations of ghrelin, insulin, and glucose of dairy cows foraging vegetative micro-swards. J. Dairy Sci. 92:2095-2105.

Gregorini, P., K. Soder, M. Sanderson, and G. Ziegler. 2009c. Toughness, particle size and chemical composition of meadow fescue (Festuca pratensis Hud.) herbage as affected by time of day. Anim. Feed Sci. Technol. 151:330-336.

Hoskin, S., K. Stafford, and T. Barry. 1995. Digestion, rumen fermentation and chewing behaviour of red deer fed fresh chicory and perennial ryegrass. J. Agric. Sci. (Camb.) 124:289-295.

Illius, A., and N. Jessop. 1996. Metabolic constraints on voluntary intake in ruminants. J. Anim. Sci. 74:3052-3062.

Kennedy, P. 1985. Effect of rumination on reduction of particle size of rumen digesta by cattle. Crop Pasture Sci. 36:819-828.

Kennedy, P., J. Dijkstra, J. Forbes, and J. France. 2005. Particle dynamics. Pages 123-156 in Quantitative Aspects of Ruminant Digestion and Metabolism. J. Dijkstra, J. M. Forbes, and J. France, ed. CABI Pub., Wallingford, UK.

Kusmartono, A., K. Shimada, K. J. Stafford, and T. N. Barry. 1996 Intra-ruminal particle size reduction in deer fed fresh perennial ryegrass (Lolium perenne) or chicory (Cichorium intybus). J. Agric. Sci. 127:525-531.

Labreveux, M., M. A. Sanderson, and M. H. Hall. 2006. Forage chicory and plantain. Agron. J. 98:231-237.

Laca, E., and M. Demment. 1991. Herbivory: The dilemma of foraging in a spatially heterogeneous food environment. Pages 30-44 in Plant Defenses Against Mammalian Herbivory. CRC Press, Boca Raton, FL.

Laca, E., E. Ungar, N. Seligman, and M. Demment. 1992. Effects of sward height and bulk density on bite dimensions of cattle grazing homogeneous swards. Grass Forage Sci. 47:91-102.

Macoon, B., L. Sollenberger, J. Moore, C. Staples, J. Fike, and K. Portier. 2003. Comparison of three techniques for estimating the forage intake of lactating dairy cows on pasture. J. Anim. Sci. 81:2357-2366.

McCoy, J., M. Collins, and C. Dougherty. 1997. Amount and quality of chicory herbage ingested by grazing cattle. Crop Sci. 37:239-242.

Murphy, M., R. Baldwin, M. Ulyatt, and L. Koong. 1983. A quantitative analysis of rumination patterns. J. Anim. Sci. 56:1236-1240.

Penning, P., A. Rook, and R. Orr. 1991. Patterns of ingestive behaviour of sheep continuously stocked on monocultures of ryegrass or white clover. Appl. Anim. Behav. Sci. 31:237-250.

Rutter, S., R. Champion, and P. Penning. 1997. An automatic system to record foraging behaviour in free-ranging ruminants. Appl. Anim. Behav. Sci. 54:185-195.

Rutter, S. M. 2000. Graze: A program to analyze recordings of the jaw movements of ruminants. Behav. Res. Methods Instrum. Comput. $32: 86-92$. 
Sanderson, M. A., M. Labreveux, M. H. Hall, and G. F. Elwinger. 2003a. Forage yield and persistence of chicory and English plantain. Crop Sci. 43:995-1000.

Sanderson, M. A., M. Labreveux, M. H. Hall, and G. F. Elwinger. 2003b. Nutritive value of chicory and English plantain forage. Crop Sci. 43:1797-1804.

Stewart, A. 1996. Plantain (Plantago lanceolata)-A potential pasture species. Proc. N.Z. Grassl. Assoc. 58:77-86.
Stockdale, C., and K. King. 1983. A comparison of two techniques used to estimate the herbage intake of lactating dairy cows in a grazing experiment. J. Agric. Sci. (Camb.) 100:227-230.

Wright, W., and A. Illius. 1995. A comparative study of the fracture properties of five grasses. Funct. Ecol. 9:269-278. 